\title{
Exploring the Impact of Perceived Teaching Style on Behavioral Intention toward Moodle Reading System
}

\author{
http://dx.doi.org/10.3991/ijet.v9i3.3500 \\ Peng-Chun Lin, Hsin-Ke Lu, Shu-Mei Fan \\ Chinese Culture University, Taiwan (R.O.C)
}

\begin{abstract}
The advances of information technology have significantly changed ways of teaching and learning in education. Compared to Computer Aided Instruction (CAI), Computer Aided Learning (CAL) is student-centered and has become one of the popular ways in learning in different fields. As we all know, the Internet has been commonly used, and a variety of e-learning systems and materials have been designed and applied in schools. Researchers have applied theoretical models, such as TAM, TPB and UTAUT to explore individuals' adoption and acceptance of technologies. In some researches, demographic individual difference has been proposed as an essential factor in adopting technologies. However, more studies have examined cognitiveoriented individual difference, especially Learning Style and Teaching Style, for users' acceptance toward system usage. In this study, we explored how Perceived Teaching Style affects ESL/EFL (English as a Second/Foreign Language) students' adoption of the Moodle Reader System by using a revised TAM. Our results indicated that the ways how Perceived Ease to Use (PE) relates to Perceived Usefulness (PU) from the two Perceived Teaching Style clusters are different. This is valuable information for English course designers or instructors when they consider incorporating e-learning projects into their curriculum. It is also useful for system designers for developing their new learning management systems. For future studies, both Learning Style and Teaching Style will be examined to find out the relationship between the two factors and how they influence system users' acceptance toward the learning management platform.
\end{abstract}

Index Terms-Perceived Teaching Styles, Individual Difference, TAM, Extensive Reading

\section{INTRODUCTION}

The development of technology and multimedia has made learning diverse and interactive. Because of the widely used Internet, learning management systems and materials have been developed and designed for different e-learning projects and programs offered by schools and companies global wide. In the field of English Language Teaching (ELT), instructors and course designers have also applied computer-assisted English learning and included e-learning components in their curriculums. Moodle Reader system which supports the Extensive Reading (ER) approach has been used in many schools and programs. This research was to explore students' adoption of the learning management system in a reading project.

In recent years, researchers have used different behavioral intention research models, such as Technology Acceptance Model (TAM), Theory of Planned Behavior
(TPB) and Unified Theory of Acceptance and Use of Technology (UTAUT) to examine users' behaviors and acceptance of e-learning systems. Many of them have regarded Demographic Individual Difference, which involves users' age, gender, education background and experience, as a key factor affecting users' acceptance [1]. However, some researches emphasized the importance of Cognitive-Oriented Individual Difference and how it affects users' system usage. Lu and Lin (2012) indicated that Learning Style and Teaching Style also have significant effects on students' behaviors and acceptance toward the learning management systems [2]. Lu et. al (2012) further indicated that previous studies have focused on teaching styles from teachers' perspective instead of students' and they have had teachers, instead of students, responding to their surveys. It was noted that the survey results from teachers and students may be different and students may have different opinions on the same instructor in terms of his or her Teaching Style [3]. Therefore, in this study we concentrated on students' perspectives by categorizing and analyzing students' response to their teacher' teaching style, that is, the perceived teaching style, to explore the effects on their adoption and acceptance of the learning management system.

\section{LITERATURE REVIEW}

\section{A. Moodle Reader and Extensive Reading (ER)}

Moodle Reader is a system that supports the extensive reading approach (ER) in English as Second or Foreign Language (ESL/EFL) programs [4,5]. The site was created by Thomas N. Robb and is used by more than 100 universities, schools and programs. It is free and provides quizzes on more than 2,000 published English graded readers and books, and that number continues to grow. The published graded readers in the system are divided into several levels according to their word counts and language complexity, which allows students to choose readers appropriate for their language proficiency levels. The system records students' work and provides a summary report that shows how many readers and total numbers of words students have read. The quizzes are randomized with a time limit. This allows students to do self-assessments and trace their own work and achievements.

The extensive reading approach has been regarded as an important part of ESL/EFL reading programs, though researchers have defined extensive reading from different perspectives. The extensive reading approach has developed into an accepted practice in ESL/EFL programs, and it encourages English students to read a lot and to read the 
topics they enjoy. As Day and Bamford (1998) noted, some ER programs use graded readers, or simplified books, as material for their reading programs [6]. A study conducted in Taiwan showed that university students in classes that allowed them to read outside of class did better than students in other classes [7]. Krashen (2004) concluded in his review of studies on in-school free reading that students in these programs often progress better than those in comparison groups [8]. In their discussion of L2 reading, Grabe and Stoller (2002) defined ER as an "approach to the teaching and learning of reading in which learners read large quantities of material that is within their linguistic competence" (p.259)[9]. Pino-Silva (2006) concluded that "ER involves (a) the reading of large amounts of L2 written material, (b) for pleasure, (c) with the purpose of learning to read by reading, and (c) graded books appear to be the basic materials on which most programs are based."[10]

\section{B. Review of Behavioral Intention Model}

A review of prior researches suggested that Technology Acceptance Model (TAM), Theory of Planned Behavior (TPB) and Unified Theory of Acceptance and Use of Technology (UTAUT) were the most prevalent theoretical models for explaining an individual's adoption of technologies. These theoretical models share the same beliefattitude-intention-behavior causality, widely accepted in numerous empirical researches.

The Technology Acceptance Model (TAM), theoretically derived from Fishbein and Ajzen's Theory of Reasoned Action (TRA), emphasizes users' beliefs, attitudes, and intentions in adopting technology $[11,12]$. Two major determinants further define the belief constructs: user's Perceived Usefulness (PU) and Perceived Ease of Use (PE). Integrated with Attitude and Intention, they form a causal chain that demonstrates users' adoption of systems. Davis (1993) revised TAM in order to better examine users' acceptance in adopting technologies. Following Davis' ideas, our researchers also revised TAM by removing the construct Intention so that Attitude directly influences learners' System Usage in the research model.

Venkatesh \& Morris (2000) similarly extended TAM's explanatory power by adding two more constructs, social norms and perceived voluntaries [14]. Social norm constructs may provide more in-depth explanations to systems usage behavior. According to the researches above, we extended the TAM by social norm construct and explore the relations between intention and system usage.

\section{Perceived Teaching Style}

"Teaching style" has been emphasized in the domain of education and educational psychology since 1930s, and researchers continually presented theoretical discussions and categorizations of teaching styles from different perspectives. Lewin, Llippit and White's(1939) leading styles had been used in teaching context, and researchers classified teaching styles into autocratic, democratic, and laissez-faire[15]. When the interactions between teachers and students had been gradually emphasized, Getzels and Thelen (1972) categorized teachers into nomothetic, idiographic, and transactional [16].

Some researchers used the instructional orientation of teachers as the classification criteria. For example, Ashley, Cohen and Slatter (1969) distinguished teaching styles into teacher-oriented, subject-oriented, and learneroriented [17]. The tutoring processes are coercive, utilitarian, and normative respectively for each style. In a similar way, Fischer and Fischer (1979) specified teachers as task-oriented, cooperative planner, child-centered, subjectcentered, learning-centered, or emotionally exciting [18].

Chen, Chen, Tseng and Kuo (2007) followed another direction and classified teaching styles by teachers' thinking styles [19]. Other than these categorizations, researchers also used metaphors when they describe teaching styles. Teachers may be as parents, mentors, pals, adults, motivator, artist, dialogist, and many more roles [20,21].

Research team in Indiana State University (Indiana State University, 2001) proposed a nine-question assessment that helps classify one into formal authority, demonstrator or personal model, facilitator, or delegator teaching style. More advancedly, Grasha (Grasha, 1990, 1994) not only proposed five teaching styles, which are styles of expert, formal authority, personal model, facilitator, and delegator, but also designed with Riechmann-Hruska a 40question questionnaire that is used to calculate the degree of each style for a teacher [22].

Based on decades of academic studies and discussions, there have been rich and outstanding results on the issue of how teaching styles affect students' learning [23][24]. However, some researchers believed that perceived and preferred teaching styles will be the effect factors of students learning [25]. In this study, researchers believe that students coming from different learning environment may have different ideas with a teacher, and Perceived Teaching Style will have different effects on students learning behavior when they use e-learning systems.

\section{RESEARCH METHOD}

This research used the revised TAM to explore Taiwanese university students' adoption and acceptance of using Moodle Reader System in their EFL program. 182 students who have finished 3 semesters of required English classes, participated in the study. In their English classes, they were encouraged to join an extensive reading project by using Moodle Reader System. The questionnaires were divided into 2 parts:

1. Behavioral Intention Questionnaire: It was based on Lu's (2012) questionnaire [13]. 25 students conducted the pre-test, and then items were revised according to the pre-test results. The official questionnaire consisted of 17 items, including 5 ones related to Perceived Usefulness (PU), 4 Perceived Ease of Use (PE), 4 Social Norm (SN), 2 Attitude (AT) and 2 System Usage (SU).

2. Perceived Teaching Style Questionnaire: Grasha's (2010) teaching style questionnaire was applied in our study [22]. However, students rather than teachers completed the survey. The questionnaire had 40 items related to the five styles, expert, formal authority, personal model, facilitator, and delegator. It was used to find out students' perceptions of their teachers' teaching styles.

For data analysis, we applied SPSS 18 and Partial Least Squares (PLS) as our analysis tools. Researchers used the software Smart PLS 2.0 developed by Ringle, Wende \& Will (2005) in Hamburg University of Germany to analyze data. PLS was developed by Wold in late 1960s. It is a statistical method used to examine or establish a prediction 
model which contains prediction and reflection attributes. It has been widely used and considered as an important tool in the fields of Information Technology and Management [26-28]. PLS is a useful method and technique for analyzing causal models which usually include both reflective and formative indicators. It is better than the Linear Structural Relation Model. This study categorized learners into two Perceived Teaching Style clusters, and each was analyzed by PLS. Paths in each cluster were again analyzed to find out their differences by multi-group analysis with PLS as shown in Figure 1.

$$
t=\frac{\text { Path }_{\text {sanuple__ }_{1}-\text { Path }_{\text {sample }_{2} 2}}}{\left[\sqrt{\frac{(m-1)^{2}}{(m+n-2)} * S \cdot E_{\text {sample } 1}^{2}+\frac{(n-1)^{2}}{(m+n-2)} * S \cdot E_{\text {scample } 2}^{2}}\right] *\left[\sqrt{\frac{1}{m}+\frac{1}{n}}\right]}
$$

Figure 1. Equation of multi-group analysis with PLS

\section{RESULTS AND DISCUSSION}

The researchers analyzed teaching styles according to Grasha-Riechman's equation and then used two step cluster analysis in SPSS to categorize the students into 2 clusters. The proportions were $21.9 \%$ and $78.1 \%$.

The 5 features respectively from the two clusters analyzed by SPSS are personal model, formal authority, expert, facilitator and delegator. The analysis results showed that personal model has stronger effect toward students than other features. Formal authority has stronger effect than expert. Expert has stronger effect than facilitator. Facilitator has stronger effect than delegator. In cluster 2, students perceived their teachers to be more involved with their learning and provide more instructions, guidance and learning activities. Thus, we called this group as 'Teacherinvolved' cluster. In cluster 1, learners felt that teachers gave them more freedom and allowed them to explore the system by themselves. According to this group of students, teachers didn't provide much guidance and rarely showed their personal characters while teaching. We called this group as 'Learner Autonomy' cluster. The relationship between the two clusters and their features are showed below.

Researchers further analyzed the two clusters by using PLS. The results are showed in Figure 2 and Figure 3. All of the paths showed below in the two clusters are significant. This means that in spite of different perceived teaching styles PE significantly affects PU and AT, and PU also has strong effect toward AT. Learners' AT also has a significant effect toward SU. As for social norm, it has a significant effect toward PU and PE respectively.

The relationships between PE and PU and that between $\mathrm{PE}$ and AT respectively in the two clusters are different. To examine the differences, researchers further studied the data by applying multi-group analysis with PLS. See the result in Table II.

The results of the multi-group analysis showed that the only and obvious difference between the two clusters in terms of their path load is the relationship between PE and PU. It is noted that in the Teacher-Involved cluster learners' perceived ease to use has less significant effect on their perceived usefulness. It seems that students didn't regard perceived ease to use as an important issue and it thus had less effect on perceived usefulness. It may be be cause their teachers' guidance and control in their learning have built up their knowledge and skills in using the system. Therefore, PE and PU didn't play an essential role in

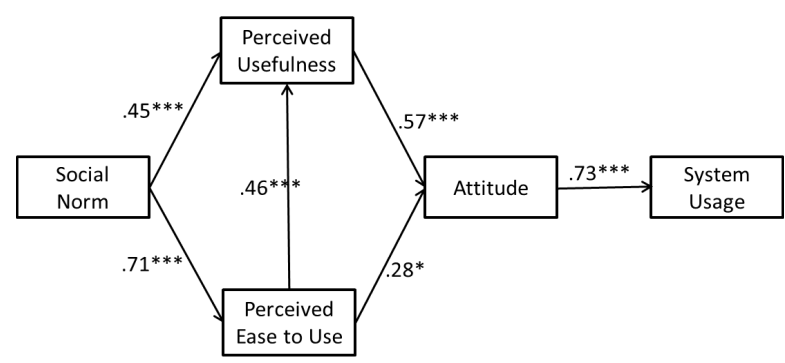

Figure 2. PLS result for cluster 1: Learner Autonomy cluster $(*:<.05 ; * *:<.01 ; * * *:<.001)$

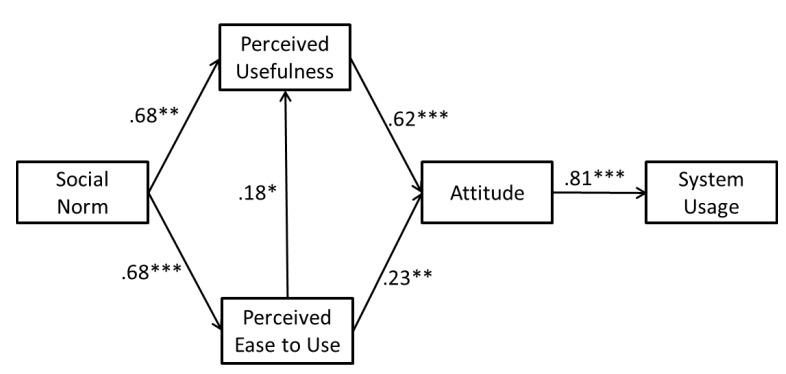

Figure 3. PLS result for cluster 2: Teacher-involved cluster $(*:<.05 ; * *:<.01 ; * * *:<.001)$

TABLE I.

Clusters AND TEACHING STYLE FEATURES

\begin{tabular}{|c|c|c|c|c|c|}
\hline \multirow{2}{*}{$\begin{array}{l}\text { Cluster } \\
\text { (Number, } \\
\text { percentage) }\end{array}$} & \multicolumn{5}{|c|}{$\begin{array}{c}\text { Teaching Style Features } \\
\text { Average } \\
\text { Level (most percentage) }\end{array}$} \\
\hline & Expert & $\begin{array}{c}\text { Formal } \\
\text { Authority }\end{array}$ & $\begin{array}{c}\text { Personal } \\
\text { Model }\end{array}$ & Facilitator & $\begin{array}{l}\text { Delega- } \\
\text { tor }\end{array}$ \\
\hline \begin{tabular}{|l|}
\multicolumn{1}{|c|}{ Learner } \\
Autonomy \\
$(40,21.9 \%)$ \\
\end{tabular} & $\begin{array}{c}3.22 \\
\text { Medium } \\
(65 \%) \\
\end{array}$ & $\begin{array}{l}3.11 \\
\text { High } \\
(45 \%) \\
\end{array}$ & $\begin{array}{c}2.92 \\
\text { Medium } \\
(78 \%) \\
\end{array}$ & $\begin{array}{c}3.12 \\
\text { Medium } \\
(73 \%) \\
\end{array}$ & $\begin{array}{l}3.17 \\
\text { High } \\
(83 \%) \\
\end{array}$ \\
\hline $\begin{array}{c}\text { Teacher- } \\
\text { involved } \\
(143,78.1 \%)\end{array}$ & \begin{tabular}{|l|}
4.24 \\
High \\
$(79 \%)$ \\
\end{tabular} & $\begin{array}{c}4.16 \\
\text { High } \\
(100 \%)\end{array}$ & $\begin{array}{c}4.19 \\
\text { High } \\
(100 \%)\end{array}$ & $\begin{array}{l}4.23 \\
\text { High } \\
(50 \%)\end{array}$ & $\begin{array}{l}4.16 \\
\text { High } \\
(100 \%)\end{array}$ \\
\hline
\end{tabular}

TABLE II.

STATISTICAL ANALYSIS RESULTS OF MULTI-GROUP ANALYSIS

\begin{tabular}{|c|c|c|c|}
\hline Path & $\begin{array}{c}\text { Learner Autono- } \\
\text { my cluster }\end{array}$ & $\begin{array}{c}\text { Teacher-involved } \\
\text { cluster }\end{array}$ & $\begin{array}{c}\text { Differences } \\
\text { between clus- } \\
\text { ters }\end{array}$ \\
\hline $\boldsymbol{S N}->\boldsymbol{P U}$ & $.45^{* * *}$ & $.68^{* * * *}$ & No \\
\hline $\boldsymbol{S N}->\boldsymbol{P E}$ & $.71^{* * *}$ & $.68^{* * * *}$ & No \\
\hline $\boldsymbol{P E}->\boldsymbol{P U}$ & $.46^{* * *}$ & $.18^{*}$ & $\underline{Y e s}$ \\
\hline $\boldsymbol{P U}->\boldsymbol{A T}$ & $.57^{* * * *}$ & $.62^{* * * *}$ & No \\
\hline $\boldsymbol{P E}->\boldsymbol{A T}$ & $.28^{*}$ & $.23^{* * *}$ & No \\
\hline $\boldsymbol{A T}$-> usage & $.73^{* * * *}$ & $.81^{* * * *}$ & No \\
\hline
\end{tabular}

their learning. On the other hand, the students in Learner Autonomy cluster didn't think they received as much guidance and instructions as the other group, so they had to learn how to use the Moodle Reader System on their own. Therefore, their perceived PE and PU played a relatively important role for them in adopting the system.

\section{CONCLUSION AND FUTURE RESEARCH}

Extensive Reading has been a popular way for students to improve their reading skills in the field of ESL/EFL [6]. The Moodle Reader System which supports extensive reading has been used in different courses or schools. In recent years, numerous researchers have explored a variety of factors that influence users' adoption and acceptance of different learning management systems, and their re- 
search results have provided system designers or educators with useful information. Among the researches, individual difference has been considered as an important factor. A lot of them focused on demographic individual difference but more studies have proved cognitiveoriented individual difference to be a dominant factor $[2,13]$. In this study, 182 EFL students who have used Moodle Reader System were divided into two clusters, Teacher-Involved and Learner Autonomy clusters. Our researchers used the revised TAM to explore these students' acceptance and use of the system.

The results indicated that all of the paths analyzed from the two clusters show significant effects on one another. However, the difference between the two clusters is the path load between PE and PU. This result implied that how much teachers have been involved in learning did affect learners' perceived ease to use and perceived usefulness. It may be because with more guidance and instructions learners didn't pay attention to usefulness and ease to use of the system. However, when students had to spend more time exploring how to use the system by themselves because of a teacher' teaching style, whether or not the system is useful and easy to use became important to them. Thus, perceived ease to use has stronger effect toward perceived usefulness in this model.

In addition to Perceived Teaching Style, Perceived Learning Style has also been considered as an essential factor in learners' system usage by researchers. In the future, our research will also examine how both Learning Style and Perceived Teaching Style relate to each other and find out to what extent different learning styles suit their perceived teaching styles. Our findings will be valuable information for instructors and system designers.

\section{REFERENCES}

[1] H. O. Awa, B. M.Nwibere, and B. J. Inyang, "The Uptake of Electronic Commerce by SMEs: A Meta Theoretical Framework Expanding the Determining Constructs of Tam and Toe Frameworks," Journal of Global Business and Technology, vol. 6(1), pp. 7-28, 2010.

[2] H. K. Lu, and P. C. Lin, "Toward an extended behavioral intention model for e-learning: Using learning and teaching styles as individual differences," 2012 Consumer Electronics, Communications and Networks (CECNet) International Conference, pp. 3673 $-3676,2012$.

[3] P. C Lin, H. K. .Lu, and C. H. Lo., "Exploring the Impact of Perceived Teaching Style on Behavioral Intention toward E-learning System, ". In proceedings of 2012 4th International Conference on Computer Technology and Development (ICCTD 2012), Thailand, 2012.

[4] P. Nation, "Teaching vocabulary in another language," Cambridge University Press, 2001. http://dx.doi.org/10.1017/CBO978 1139524759

[5] R. Waring, and M. Takaki, "At what rate do learners learn and retain new vocabulary from reading a graded reader?" Reading in a Foreign Language, vol. 15(2), pp. 130-163, 2003.

[6] R. Day, and J. Bamford, "Extensive Reading in the Second Language Classroom”, Cambridge: CUP, 1998.

[7] C. K. Liu, "Self-selected reading effects significant gains in vocabulary size an reading comprehension," Paper presented at English Teachers Association Conference, Taiwan, 2005.

[8] S. D. Krashen, “The Power of Reading”, Second edition. Portsmouth, NH: Heinemann Publishing Company, 2004.

[9] W. Grabe, and F. L. Stoller, "Teaching and researching reading", Pearson Education. New York, 2002.

[10] P. S. Juan, "Extensive reading through the internet: is it worth the while?" International Journal of English Studies, vol. 9(2), pp. 8196, 2009.
[11] F. D. Davis, "Perceived usefulness, perceived ease of use and enduser acceptance of information technology," MIS Quarterly, vol.13, pp. 318-339, 1989a. http://dx.doi.org/10.2307/249008

[12] F. D. Davis, "User acceptance of computer technology: A comparison of two theoretical models," Management Science, vol. 35(8), pp. 982-1003, 1989b. http://dx.doi.org/10.1287/mnsc.35.8.982

[13] H. K. Lu, "Learning Styles and Acceptance of e-Learning Management Systems: An Extension of Behaviour Intention Model," International Journal of Mobile Learning and Organisation $\begin{array}{llll}\text { (IJMLO), vol. } & 6(3 / 4), & \text { pp. } & 246-259,\end{array}$ http://dx.doi.org/10.1504/IJMLO.2012.050044

[14] V., Venkatesh, and M. G. Morris, "Why Don't Men Ever Stop to Ask for Directions? Gender, Social Influence, and Their Role in Technology Acceptance and Usage Behavior," MIS Quarterly, vol. 24(1), pp. 115-139, 2000. http://dx.doi.org/10.2307/3250981

[15] Lewin, K., LIippit, R., and White, R. K. (1939). Patterns of aggressive behavior in experimentally created social climates. Journal of Social Psychology, 10, 271-301. http://dx.doi.org/10.1080/ $\underline{00224545.1939 .9713366}$

[16] J. W. Getzels, and H. A. Thelen, "A conceptual framework for the study of the classroom group as a social system," In A. Morrison \& D. Mcintyre (Eds.), The Social Psychology of teaching. New York: Penguin Books Ltd., 1972.

[17] B. J. Ashley, H. S. Cohen, and R. G. Slatter, "An Introduction to the Sociology of Education," London: Macmillan, 1969.

[18] B. B. Fischer, and L. Fischer, "Styles in teaching and learning," Educational Leadership, vol. 36(4), pp. 245-254, 1979.

[19] Y. F. Chen, H. Z. Chen, S. C. Tseng, and B. C. Kuo," Measurements of teaching styles for computering teacher, " Paper presented at the 2007 National computer symposium, Taipei, 2007.

[20] A. F. Grasha, "A matter of style: The Teacher as Expert, Formal Authority, Personal Model, Facilitator, and Delegator," College $\begin{array}{llll}\text { Teaching, vol. 42(4), pp. 142-149, } & 1994 .\end{array}$ http://dx.doi.org/10.1080/87567555.1994.9926845

[21] A. Kraft, “The Living Classroom. Putting Humanistic Education into Practice," New York: Harper \& Row, 1975.

[22] A. F. Grasha, "A Grasha-Riechmann Teaching Style Survey," Retrieved Sep. 1, 2013, from http://www.longleaf.net/ teachingstyle.html, 2003

[23] M. Haenlein, and A. M. Kaplan, "A Beginner's Guide to Partial Least Squares Analysis," UNDERSTANDING STATISTICS, vol. $3(4)$, pp. 283-297, 2004. http://dx.doi.org/10.1207/ s15328031us0304_4

[24] J. Onur, "A study of the effects on teaching methods and teaching styles of converging national and international curricula at the Koc School," $\quad$ Retrieved Sep. 1, 2013, from http://opus.bath.ac.uk/18786/, 2008.

[25] N. A. Razak, F. Ahmad, and P. M. Shah, "Perceived and preferred teaching styles (methods) of english for specific purposes (ESP) Students," Jurnal e-Bangi, vol. 2(2), pp. 1-20, 2007.

[26] J. K. Johansson and G. S. Yip, "Exploiting Globalization Potential: U.S. and Japanese Strategies," Strategic Management Journal, vol. 15 , pp. 579-601, 1994. http://dx.doi.org/10.1002/smj.4250150802

[27] N. Bontis, "Intellectual capital: an exploratory study that develops measures and models," Management Decision, vol. 36(2), pp. 6376, 1998. http://dx.doi.org/10.1108/00251749810204142

[28] B. H. Wixom, and H. J. Waston, "An empirical investigation of the factors affecting data warehousing success," MIS Quarterly, vol. $25(1)$, pp. 17-41, 2001. http://dx.doi.org/10.2307/3250957

\section{AUTHORS}

Peng-Chun Lin is with the Information Management Department, School of Continuing Education, Chinese Culture University, Taiwan (R.O.C)

Hsin-Ke Lu is with the Institute of Information Management, School of Continuing Education, Chinese Culture University, Taiwan (R.O.C)

Shu-Mei Fan is with the School of Continuing Education, Chinese Culture University, Taiwan (R.O.C)

Submitted 29 December 2013. Published as re-submitted by the authors 18 May 2014. 